\title{
Interactive Roles of Social Identity and Evaluative Attitudes in Sports Events Participation
}

\author{
Suosheng Wang, Wei Wang, Soonhwan Lee
}

\begin{abstract}
The impacts of sense of place and place-based social identity have been widely discussed in tourism literature. Both identity theorists and planned behavior researchers suggested that identity and evaluative attitudes exert influence on consumers' behavioral intent. Yet, few studies have ever examined how one's social identity and evaluative attitudes interact on consumers' behavioral intent. This study aims to fill this gap by examining the role of one's social identity in the process of planned behavior in the context of sports events participation. Based on a survey on college students, this study verifies that social identity significantly influences one's behavioral intention of attending sports events, directly and indirectly via the mediating effects of evaluative attitudes. Notably, the influential roles are mainly implemented by affective social identity, not cognitive social identity. This study indicates that the inclusion of one's social identity in the conceptual framework of planned behavior helps better understand people' involvement in sports events. Both theoretical contributions and practical implications are discussed.
\end{abstract}

Keywords: social identity; cognitive and affective components; evaluative attitudes; sports events and festivals; college students

This is the author's manuscript of the article published in final edited form as:

Wang, S., Wang, W., \& Lee, S. (2018). Interactive roles of social identity and evaluative attitudes in sports events participation. Journal of Convention \& Event Tourism, 0(0), 1-20. https://doi.org/10.1080/15470148.2018.1488640 


\section{INTRODUCTION}

Cities especially in the developed countries have been affected by declining manufacturing firms once key to a city's economic prosperity. As a result, cities like Indianapolis make efforts to seek new avenues for economic development, and have turned to urban cultural tourism, such as conventions, sports events and festivals as part of development strategies. In Indianapolis, sport events and festivals offer an opportunity for branding the city externally, potentially attracting new economic revenues, while at the same time reconstructing its place image, of which the city residents feel proud.

Regarding sports events and festivals development, it is essential to gain an understanding of the residents' opinions. Not including residents' opinions or disregarding them can have economic and social consequences, which include an unwillingness to work in the industry and lack of enthusiasm for promotion of tourism by word of mouth (Pearce, 1998). Without community support, it "is difficult to develop a sustainable tourism industry in the community" (Andereck \& Vogt, 2000, p. 27). Sports events and festivals are as much, if not more, a place maker as tourism (Nauright, 1996) which is asserted to be one of the most significant shapers of collective or group identity in the contemporary world. Not only does sport provide insight into the identity of a group but it can also provide accessible insight into the identity of a place.

The nature and strength of residents' place identity and attachment to community and surrounding landscape may be important determinants of successful coexistence between residents and the tourism industry (McCool \& Martin, 1994). Therefore, addressing the place- 
based views and concerns of residents is critical in maintaining public support for tourism (Andereck \& Vogt, 2000); and the active support of host communities can be crucial for sustainable tourism development.

Previous studies suggest that people's identity influences their attitudes and behaviors (Wang \& Xu, 2015; Wang \& Chen, 2015). Research undertaken by Becken (2007) indicates that tourists see travel as part of their identity; their holidays have a great meaning to them and help them understand their positions in society. While many tourism studies focus on how tourism activities help affirm visitors' self-identity, relatively, few has ever examined the role of selfidentity on one's tourism behavior. Desforges (2000) suggests that understanding identity can lead to an insight into tourism consumption, because by understanding the people and their needs and desires, it is possible to predict their future consumption patterns.

In contrast, the theory of planned behavior (TPB) (Ajzen, 1985) is about attitudebehavior relationship. The literature indicates that evaluative attitudes may be distinguishable from identity-related symbolic outcomes (e.g., McCracken, 1986). While researchers aligned with the TPB may consider one's self-identity to be reflected in the person's beliefs, values and attitudes (Sparks \& Shepherd, 1992), there is a body of empirical studies indicating the importance of self-identity in the overall structure of the TPB (e.g., Stets \& Biga, 2003; Strack \& Deutsch, 2004; Hagger, Anderson, Kyriakaki, \& Darkings, 2007). For instance, Hagger, et al. (2007) examined the effects of self-identity on behavioral intentions in the context of TPB for three health behaviors, i.e., exercise, dieting, and binge drinking, but failed to identify direct effects of the identity constructs on behavioral intentions. Charng, Piliavin and Callero (1998) suggest that self-identity may influence one's behavioral intention independent of evaluative attitudes. 
Attitude research and identity research have both attracted a big amount of research interest in the context of tourism research. A few studies have ever examined the interactive role of one's identity and evaluative attitudes on behavioral intentions (e.g., Hagger et al., 2007; Wang \& Xu, 2016; Wang \& Chen, 2016). Attending sports-related events and festivals is a special recreational activity favored by people, however, no empirical inquiries in this regard seems to have ever been conducted in the context of participating in sports events and festivals, and the relationship between identity and attitude toward recreational behaviors remains unknown. Drawing on the theories of social identity and planned behavior, this study aims to fill this gap by testing how the aspects of social identity are associated with people's evaluative attitudes toward recreational behaviors, in the context of sports events and festivals.

\section{LITERATURE REVIEW}

Literature review is conducted in relation to the theory of social identity, the theory of perceived behavior, interactive relations between social identity components and TPB components, as well as their impacts on people's intentional behavior to attend local sports events and festivals.

\subsection{Sense of Place and Place-based Social Identity}

Sense of place can be described as a compilation of meanings, knowledge, attachment, commitment and satisfaction that an individual or group associates with a particular place. Sense of place is based on the need to belong not to something in the abstract, but to somewhere in particular, thus allowing people to experience commitment and loyalty (Sennett, 1999). Bauman (2001) has reasoned that people are searching for a sense of belonging and civic participation 
because they have become physically isolated. 'The physical proximity and social distance of the modern city causes people to seek out ways to connect with each other, rediscovering the sense of "community" we nostalgically believe once existed' (Smith \& Ingham, 2003: 259). Place satisfaction is an aspect of sense of place and deals with how a place meets or fails to meet preconceived expectations, needs or standards of quality of life that a person holds (Shamai, 1991; Stedman, 2002). According to Stets \& Biga (2003), an identity is "a set of meanings attached to the self that serves as a standard or reference that guides behavior in situations ( $\mathrm{p}$. 401)." A place identity is determined not only by the physical components but also the meaning and association developed between people and place (Bott, Cantril, \& Myers, 2003).

An earlier well established place-related identity theory is the social identity theory (SIT) (Tajfel, 1972) which, when applied to place-behavior studies, focuses more on interrelationship between place, place attachment and individuals' pride and self-esteem. The social identity theory is primarily described as a theory that predicts certain intergroup behaviors based on individuals' social identification. Social identity is described as the individual's knowledge of belonging to certain social groups, as well as the emotions and values this conveys to him or her (Tajfel, 1982). Place-related social identity depends on the quality of the place we belong to or have as a positive reference, such as nationality, culture, religion, neighborhood, etc. Gu \& Ryan (2008) postulates that being a city's resident can be a source of pride if the resident feels it a boost to his or her self-esteem.

\subsection{Social Identity Components - Cognitive and Affective}

Previous scholars suggest social identity to be composed of three components, i.e. cognitive, evaluative, and emotional (Ellemers, Kortekaas, \& Ouweerkerk, 1999, in Palme et al., 2013). According to Ellemers et al. (1999), the cognitive component is associated with a 
cognitive awareness of one's membership in a social group or self-categorization; the evaluative component is linked to group self-esteem, and related to the positive or negative value connotation attached to a particular group membership; and the third component of identity relates to the affective commitment to the group - the emotional aspect of social identification. When applying these three components in an empirical place-behavior study, Palme et al. (2013) noticed a high correlation and poor discriminant validity between the constructs of 'evaluative' and 'emotional'. As a result, Palme et al. (2013) suggested to combine the two nominally different constructs into one component labeled as 'affective component'.

Identity can be predominately cognitive, referring to evaluations based on identification with practical benefits associated with the area; or affective, referring to deeply held but not necessarily rational beliefs about the area (Collins, 2000). According to Albert, Ashforth, Barker, Dukerich, Elsbach, Glynn, Allen, Long, Perdue, \& Kieselbach (1998), original conceptualizations of social identity include both cognitive and affective components. Cognitively, social identity provides a way for individuals to place themselves and others in society such that individuals define themselves as organization members. Affectively, social identity provides a sense of pride in and belongingness to the group, and reflect the value of that identity to the group member. Based on the literature, this study will focus on the two social identity components - cognitive social identity and affective social identity.

Literature indicates that a person's identity influences his or her attitudes and behaviors (Hagger, et al., 2007). Self-identity perceptions may affect individuals' intentional behaviors by serving as a source of information when people make plans to act (Hagger et al., 2007). Placebased identity influences resident's support for tourism, and that self-identity is a good determinant of behavior (Nunkoo \& Gursoy, 2012). According to Sukoco \& Wu (2010), the 
strength of residents' social identity is positively related to their likelihood of sharing their knowledge with non-locals. For example, a person who claims to be an Indy 500 fan may more likely participate in Indy 500 related events and festivals. Based on these assertions, it is posited that one's participation in sports events and festivals can be highly motivated by his sense of social identity, and place-based social identity is crucial for understanding how to enhance local people's participation in sports events and festivals.

\subsection{TPB Components - Attitudes, Subjective Norm, Perceived Behavioral Control}

The theory of planned behavior (Ajzen, 1985) has emerged as an influential social cognitive model widely applied to understanding people's intentional behaviors. The main concept of TPB is that most human behavior is under volitional control; people engage in actions because they want to act in a certain behavioral way, and their conscious motives trigger them to engage in that action (Ajzen \& Fishbein, 1980). The TPB suggests that behavioral achievement depends on three types of beliefs - attitude, subjective norm, and perceived behavioral control. Among them, attitude toward a behavior is, at the most basic level, a function of behavioral beliefs and outcome evaluations (Ajzen, 1991). Attitudes toward a specific behavior are theorized to have a direct effect on their intentions to perform the behaviors (Ajzen, 1988).

The second TPB component is subjective norm, which refers to one's perceived social pressure from important others (such as relatives, friends, and colleagues) to perform or not to perform a behavior (Ajzen \& Fishbein, 1980). It is believed that people are more likely to perform a behavior when they receive support from their referents than when they do not (Ajzen \& Fishbein, 1980). In the context of sports events, if your close friends or relatives all think that it is great to attend certain types of sports events, it is more likely for your intention of sports events participation to arise as compared to visiting other destinations. The third TPB component 
is perceived behavioral control, which is the degree to which an individual feels that the performance or nonperformance of a behavior in question is under his or her volitional control (Ajzen, 1985, 1988), which, in the context of sports events, is about one's perception of participation constraints or inhibitors, such as physical mobility, disposable income, and leisure time.

Based on the above, this study posits that the three primary TPB components - attitude, subjective norm, and perceived behavioral control - significantly influence one's behavioral intentions to participate in sports events and festivals.

\subsection{Interactive Effects of Social Identity and Evaluative Attitudes}

Despite its effectiveness in explaining people's behavior intentions, Ajzen (1985) suggests that the TPB model be viewed as a flexible theoretical framework to explain the psychological influence on intentional behavior, and other independent variables can be encompassed provided they increase the predictive validity of the theory. That said, the TPB model does not account for all the variance in predicted behavior and considerable variance may remain unexplained. As such, the TPB model may not be able to provide a complete view as to why people perform a certain behavior, and researchers should look for other important variables which contribute to the predicting power of the model. In this vein, recent research has highlighted the importance of integrating the role of identity in predicting people's behavioral intentions within the conceptual structure of TPB (e.g., Hagger, Anderson, Kyriakaki \& Darkings, 2007).

Apart from Hagger et al.'s study (2007), few studies have ever examined the mediating role of TPB components when investigating the effects of social identity on human behavioral 
intentions (Hagger et al., 2007); nevertheless, none seems to have been conducted in the field of sports events and festivals. Based on the aforementioned literature review, to test the posited relationships between the social identity components and TPB components as well as their interactive role on intentional behaviors, a conceptual research framework about people's participation in sports events and festivals is developed (see Figure 1).

$<$ Insert Fig. 1 here $>$

As shown in Figure 1, eleven hypothetical relations are developed as shown below which are tested in this study:

H1\&2: Cognitive and affective social identities significantly influence attitude on one's behavioral intentions, respectively;

H3\&4: Cognitive and affective social identities significantly influence subjective norm on one's behavioral intentions, respectively;

H5\&6: Cognitive and affective social identities significantly influence perceived behavioral control on one's behavioral intentions, respectively;

H7,8\&9: The TPB's attitude, subjective norm, and perceived behavioral control significantly influence behavioral intentions, respectively;

H10\&11: Cognitive and affective social identities have significant direct impacts on behavioral intentions, respectively. 


\section{RESEARCH METHODS}

This study is conducted in the city of Indianapolis of the United States, with a focus on college students' participation in the city's 500 Festival. This section introduces the background of Indy 500 Festival, questionnaire design, data collection and analysis.

\subsection{Place of study - Indianapolis and Indy 500 Festival}

The city of Indianapolis and its residents have a long history of identifying with sports. The Indianapolis 500 is an automobile race held annually at Indianapolis Motor Speedway in Speedway, Indiana, USA. The event is held over Memorial Day weekend in late May. The sport event is considered part of the Triple Crown of Motorsport, which comprises three of the most prestigious motorsports events in the world, also including the Monaco Grand Prix and the 24 Hours of Le Mans. The Indianapolis 500 car race has been a major draw for visitors to the city. The venue itself has over 250,000 permanent seats, and the total attendance is up to approximately 300,000 (Visit Indy, 2017). The name of the race is often shortened to Indy 500.

No other organization captures the significance of the month-long celebration surrounding the Indy 500 quite like the 500 Festival. The 500 Festival, a not-for-profit volunteer organization, was created in 1957 to organize civic events celebrating the Indy 500. Over years later, the 500 Festival is one of the largest and most respected festivals in the nation, adding to the quality of life for Indiana's citizens and their guests (Visit Indy, 2017). Key 500 Festival events include: the OneAmerica 500 Festival Mini-Marathon; the 500 Festival mini-mini; JPMorgan Chase 500 Festival Kid's Day \& Rookie Run; the 500 Festival Breakfast at the Brickyard, presented by Midwestern Engineers, Inc. (held at the Indianapolis Motor Speedway); the 500 Festival Memorial Service, presented by Rolls-Royce; the IPL 500 Festival Parade and 
the KeyBank 500 Festival Snakepit Ball. Each year, the 500 Festival brings more than half a million people to the heart of Indiana to celebrate the magical month of May (Visit Indy, 2017).

\subsection{Questionnaire Design}

The survey instrument is a cross-sectional questionnaire, consisting of three sections. The first section contains items measuring the TPB constructs of attitude, subjective norm, and perceived behavioral control, respectively; the second section includes the measures of the two components of social identity - cognitive identity and affective identity; and the third section refers to respondents' demographic characteristics.

Semantic scaling questions anchored with bipolar adjectives are used to measure the construct of 'attitude,' as are typically used in tourism studies (Baloglu \& Mangaloglu, 2001). The bipolar adjectives are unfavorable/favorable, unpleasant/ pleasant, boring/exciting, and foolish/fun. It is noted that previous studies used one single item (e.g., Song, Lee, Norman \& Han, 2002) to measure 'subjective norm.' According to Armitage and Conner (2001), a singleitem measure of 'subjective norm' may become a weak predictor of behavioral intentions, hence three items are used to measure the construct of 'subjective norm', which are "People important to me like to see me attend Indy 500 Festival," "My friends/relatives/colleagues support me to join in Indy 500 Festival," and "People important to me agree I participate in Indy 500 Festival." The items used to measure 'perceived behavioral control' are adopted from Song et al. (2012), which are "I think I can visit or revisit Indy 500 Festival whenever I want," "I think that I am capable of participating in Indy 500 Festival," "I am sure I have necessary resources (e.g. money, leisure time, etc.) to attend Indy 500 Festival." Besides, three items are used to measure the construct of 'behavioral intentions' which are "I am willing to attend this year or next year's 
Indy 500 Festival," "I intend to participate in Indy 500 Festival this year or next year," and "I will visit/revisit Indy 500 Festival this year or next year."

The aspects of social identity questionnaire conceptualize the self as a dual identity structure comprised of both cognitive social identity and affective social identity. To measure the two aspects of social identity constructs, this survey instrument adopts the items applied by Wang and $\mathrm{Xu}$ (2016). One example of the items measuring cognitive social identity is "I consider myself an Indianapolis resident," and one example of affective social identity items is "I am proud of being an Indianapolis resident." All the items adopted a seven-point Likert scale ranging from strongly disagree (1) to strongly agree (7).

Prior to the survey, a pilot test was conducted. The survey instrument was presented to 40 senior college students majoring in tourism management who were all living in Indianapolis. The students were asked to comment on the clarity and relevance of the items to the TPB and social identity components, hence suggestions regarding the phrasing of statements were made. The comments and suggestions were reviewed and the instrument was modified accordingly.

\subsection{Data Collection and Analysis}

A self-administered survey was conducted online via the Qualtrics in the form of a research project assigned to the undergraduate students who were taking a tourism research course in the spring and fall semesters, 2016. Using a snowballing approach, students reached out to the other students on campus through emails, distributing and collecting data via the Qualtrics. As a result, a total of 457 usable surveys were collected. 
Upon completion of the data collection, the data were screened for violations of underlying assumptions based on descriptive statistics, using the Statistical Package for the Social Sciences (SPSS 23). Each of the univariate distributions has skew and kurtosis within reasonable ranges ( $<3$ and $<10$, respectively), the values falling within the guidelines and being regarded fairly normal for further structural equation modeling analyses (Kline, 2005). The data were then analyzed with LISREL (8.80), which is a statistical analytic software, to run the covariance structure analysis. This approach advocates initially estimating a measurement model and then a structural equation model. The goodness of fit indicators demonstrating a good fit for the structural model was inspected, based on the indices of $\chi 2 / \mathrm{df}$, p-value, comparative fit index (CFI), normative fit index (NFI) and root mean square error of approximation (RMSEA). This study hypothesized that the aspects of social identity may not only exert direct effects, but also indirect effects on behavioral intentions mediated by TPB components, thus as for the two social identity constructs, their direct, indirect and total effects are also examined.

\section{RESULTS}

Of the 457 participants, $41.8 \%$ are male and $58.2 \%$ are female students. In terms of schooling years, the mode is senior students (39.4\%); both juniors and sophomores account for $19.6 \%$ each; about $14.6 \%$ are freshmen and $6.8 \%$ are graduate students. Among them, $27.2 \%$ have attended the Indy 500 festival once, $18.3 \%$ twice, $15.1 \%$ three times, $10.5 \%$ four times, $6.7 \%$ five times, $12.2 \%$ over five times, and only $10 \%$ have not attended the festival yet.

Based on the mean scores of the items, the summated mean scores of the constructs, from the highest to the lowest, were Cognitive Identity (5.41), Attitude (5.29), Subjective Norm (5.21), Behavioral Intention to attend the festival (4.79), Affective Identity (4.57), and Perceived Behavioral Control (4.52). The results indicate that, generally, the respondents' perceptions of 
the TPB and self-identity constructs are mildly positive, ranging from $4.52-5.41$. Among the constructs, Cognitive Identity received the highest mean score (5.41), and Perceived Behavioral Control obtained the lowest (4.52). With Lisrel 8.80, the goodness of fit tests of the posited measurement model and structural model were conducted. Confirmatory factor analysis (CFA) of the constructs - cognitive identity (CI), affective identity (AI), attitude toward Indy 500 festivals (ATT), subjective norm (SN), perceived behavioral control (PBC), and behavioral intention to attend Indy 500 festivals (BI) - was conducted.

The fit indices were: Goodness-of-fit statistics $x^{2}(194)=679.09, \mathrm{p}<.001, \mathrm{NFI}=0.97$, $\mathrm{CFI}=0.98$, and RMSEA $=.072$. Overall, the measurement model showed a good fit for the data (MacCallum, Brown, \& Sugawara, 1996). Convergent validity was assessed by the significant loadings between the observed variables and each latent variable. All the observed variables were loaded above .40 on their delegated latent variables and were statistically significant $(\mathrm{p}<.01)$. As shown in Table 1, all the average variance extracted (AVE) values were .40 or higher, ranging from .555 to .796 , which supported adequate internal consistency. Next, the composite reliabilities of all constructs exceeded the cutoff value of .70 (Hair, Anderson, Tatham, \& Black, 1998). The Cronbach's alpha values of the constructs range from .785 to .921, thus the multiple item scales were acceptable for measuring each of the constructs. To compare the AVE with the squared correlations between constructs for discriminant validity testing (Fornell \& Larcker, 1981), the squared correlations between each pair of constructs were all less than the AVE values. Thus, discriminant validity was satisfied. Overall, the measurement model shows a good fit to the data.

$<$ Insert Table 1 here $>$ 
The structural model was estimated to examine the hypothetical relations. The results showed that the goodness-of-fit indices (goodness-of-fit statistics: $x^{2}=933.41(\mathrm{df}=197, p$ $<.001), \mathrm{RMSEA}=0.079, \mathrm{CFI}=0.97, \mathrm{NFI}=0.96)$ were all within their acceptable level, suggesting that the model is adequate. The constructs of Social Identity explained $37 \%, 52 \%$, and $31 \%$ of the variances in Attitude, Subjective Norm, and Perceived Behavioral Control, respectively, then the social identity components and TPB components altogether explained $73 \%$ of the variance in the construct of Behavioral Intention, indicating a good fit of the proposed structural model.

Table 2 shows the paths' standardized coefficients and the corresponding $t$ values. The significant paths include both the Gamma paths (relationships between exogenous constructs and endogenous constructs) and the Eta paths (relationships between endogenous constructs) in the model. Based on the $t$ values, eight out of the eleven hypothetical paths showed to be significant. All the significant paths indicate positive relations; all the three TPB components (attitude, subjective norm, and perceived behavioral control) made significant impacts on people's behavioral intentions to attend Indy 500 festivals. It is noted that the three insignificant paths were from Cognitive Social Identity to Attitude, Perceived Behavior Control, and Behavioral Intentions to attend Indy 500 festivals, respectively.

\section{$<$ Insert Table 2 here $>$}

Both the indirect effects and total effects of cognitive social identity and affective social identity were examined (see Table 3), which were compared to their direct effects as displayed in Table 2. It shows that cognitive social identity's indirect impact is significant; its direct impact seems to be suppressed by the indirect effect as the total effect turns out to be of no significance. In contrast, affective social identity shows all the indirect, indirect, and thus total effects. As a 
result, this study proves that one's social identity exerts both direct and indirect influences on his behavioral intention to attend the Indy 500 Festival, and such impacts are mainly made through one's affective social identity, not cognitive social identity. Hence, based on the results as shown in Tables 2 and 3, except 'cognitive social identity', all the other factors ('affective social identity', 'attitude', 'subjective norm', and 'perceived behavioral control') have significant positive impacts on 'behavioral intention'.

\section{$<$ Insert Table 3 here $>$}

The moderated multiple regression analyses (Aguinis, 2004) were conducted to determine whether a moderating effect of "past participation' exists, which entails the addition of an interaction term in a multiple regression model. The results of the analyses were reported in Table 4, with only the models showing significant interaction-term incremental variance being illustrated. The results indicate that the structural equation model is partially moderated by the respondents' past participation in the event. Specifically, the variable of 'past participation' moderates the relations between $\mathrm{AI}$ and $\mathrm{PBC}, \mathrm{CI}$ and $\mathrm{SN}, \mathrm{AI}$ and $\mathrm{BI}, \mathrm{ATT}$ and $\mathrm{BI}$, and PBC and BI, as shown in Step One in Table 4. The results in Step Two further shows that all these significant relations are stronger for people with high past participation (arbitrarily 3 times or more) than the ones with low or no past participation (arbitrarily 2 times or less).

$<$ Insert Table 4 here $>$

\section{DISCUSSIONS AND CONCLUSION}

The results of this study show that the aspects of social identity have significant effects on people's behavioral intentions to attend sports events and festivals. It is observed that social identity impacts people's behavioral intentions directly, and indirectly through the mediation of the TPB evaluative attitudes. It indicates that the local people's social identity concerns are 
salient when responding to the evaluative scales typically used to tap attitude toward behaviors. All the three TPB components - Attitudes, Subjective Norm, and Perceived Behavioral Control are significant in mediating the relationship between social identity and local people's intentional behaviors. In other words, social identity exerts indirect effects on behavioral intentions within the assessment model of the theory of planned behavior.

In terms of the mediating roles of the TPB components, first, this study verifies that the affective social identity can make impacts on behavioral intentions to attend sports events and festivals through the mediation of TPB's Attitude. In other words, one's cognition of his affective social image affect his attitude toward sports events and festivals participation intentions. For instance, a college student who feels proud of being Indianapolis resident will be more likely to adopt the idea of joining in the Indy 500 event and festival celebrations. Second, the indirect effect of affective social identity is found to be mediated by the construct of Subjective Norm. A person's sense of self is inextricably linked with the norms of the in-group which suggests that one's identity considerations are likely to influence normatively-endorsed behavior (Tajfel, 1981). The association between the aspects of social identity and perceived subjective norm could be due to people's common cognition of engaging community events and festivals as one's important social activity and community engagement. Third, the indirect effect of affective social identity is found to be mediated also by the construct of perceived behavioral control. In other words, the construct of PBC significantly mediates the effect of affective social identity. When a college student plans to attend the sports events and festivals, he would tend to assure himself that he is capable of taking part in these events and festivals.

The results of this study reinforce the cognition that the affective social identity significantly contributes to college students' behavioral intentions to attend the Indy 500 
Festival. Hence it is recommended that, assessment of local people's participation in sports events and festivals should consider the impacts of not only the TPB factors but also the social identity factors. This study shows that affective social identity acts as an independent predictor of local people's participation; in addition, it makes indirect impacts on people's participation through the mediating effects of the evaluative attitudes embedded in TPB.

This study indicates that, in the context of sports events and festivals participation, it is the affective social identity which makes the significant direct and indirect impacts; no significance was noticed for the cognitive social effects. This result logically makes sense when discerning the conceptual meanings of cognitive and affective social identities. A cognitive evaluation refers to the beliefs or the knowledge about one's identity with the place while an affective evaluation refers to feelings or emotional responses towards the identity with the place. In other words, a cognitive component is more related to functional aspects while an affective one is more associated with psychological aspects (Gartner, 1996; Baloglu \& Mangaloglu, 2001). Every local resident may cognitively feel a sense of belongingness to a place, however, not everyone necessarily feels emotionally attached to it, or feels proud of being part of it. Only those who feel proud of being a member of the place may be more highly motivated to attend the local events and festivals. The result indicates that, in the context of sports events and festivals, the effects of the affective social identity is more prevalent than that of the cognitive social identity. A college student who feels emotionally attached to the city of Indy or proud of being the city citizen will be more likely to participate in the 500 Festival than the ones who only cognitively consider themselves as residents of the city.

This study verifies that affective social identity act as ab important antecedent to the TPB factors in predicting sports events and festivals participation intentions. The evaluative attitudes 
embedded in the TPB are formulated on the basis of situational evaluations or utilitarian outcomes which are more decisive in explaining destination choice, while the place-based social identity is functioning based on the feelings of social belongings and self-esteem attached to the place. By identifying the relationships between place-based social identity and the TPB components, this study integrates the two theories in explaining local people's sports events participation intentions, and stresses the importance of incorporating the element of social identity when applying the TPB to assess local people's evaluative attitudes toward sports events and festivals.

The results show that the college students are more likely motivated to attend the sports events and festivals which are interesting, affordable, and shared by friends, but also have the vigor to meet their needs of social belonging and self-esteem. Consumers often prefer the brands or the products which have a high level of congruence with self-image (Sirgy, 1986) and associating the specific personality features to the brands allows the consumer to express a certain conception of himself, so as to acquire some value-enhancing, symbolic benefits from a given consumption (Vernette, 2003).

In terms of managerial implications, what's usually covered in sports events marketing campaigns, brochures or websites are more about the appeal and excitement of the events; what could be overlooked are the people's prospects of symbolic outcomes. The results of this study indicates that the sports events and festivals which best meet the local people's desires for reaffirming affective social identity will help augment his evaluative attitudes, which in turn reinforce his participation intentions. It implies that the event planning should reflect the importance of meeting local people's needs for affective social identity. The event organizations and planners may consider incorporating some activities aiming to enhance the participants' self- 
esteem and proudness of social belonging as a city resident. In terms of sports events and festivals marketing, the implication is that the event/festival management organizations should not only promote the inherent attributes and the characteristics of the events or festivals, but also identify and highlight the events or festivals' personality features. Articulating and promoting the events and festivals' personality features will boost the people's participation whose social identity is found to be congruent with the event's personality features. The development legacies associated with organizing sports events and festivals may be aimed at local communities in a deliberate bid to promote healthy living and, in doing so, build local place identity that is desirable and attractive.

The moderating role of previous participation indicates that the relationships as illustrated in Fig. 1 tend to turn stronger for those who have already participated over times in the festival. This result shows that the role of social identity and/or evaluative beliefs on intentional behavior of participation for new comers may not be as strong as for frequent visitors, and it may take time for the participants to become more aware of the merits of participation. This implies that the festival organization and event planners should focus their marketing efforts more on the new visitors, for example by providing experiential learning, community service or volunteering opportunities to college students or holding a welcome/educational ceremony for new participants and/or recognition ceremony for loyal participants.

With regards to the theoretical contributions, this study provides a different perspective in understanding the roles of one's social identity in the process of formulating one's evaluative attitudes and behavioral intentions in the context of sports event and festivals. Few studies have ever attempted to examine the interactive roles of social identity and TPB components in understanding consumption behaviors. This study represents an initial effort to explore the 
relationships in this regard. This study empirically verifies the existence of both the direct and indirect effects of affective social identity in the context of sports events and festivals. Thus it is recommended a more comprehensive inquiry of local people's event/festival participation based on the predicting model of TPB should consider incorporating the variables of social identity.

For future studies, it is suggested that a reciprocal relationship may exist between placebased social identity and behavioral intentions to attend sports events and festivals. Sports event is one of the most significant shapers of collective or group identity (Nauright, 1996); not only does sport provide insight into the identity of a group but it can also provide accessible insight into the identity of a place. In turn, as shown in this study, social identity positively influences people's intentions to attend sports event. Therefore, future studies should consider applying experimental research to test the reciprocal relationship between social identity and sports events and festivals participation.

One major limitation of this study is that the data which were collected with a nonrandom snowballing sampling approach, hence possible sampling errors could occur and the results might not be free from bias. More studies of the same kind are recommended to test the generalizability of the result, and if possible, a random-sampling approach should be preferred. Another consideration is to expand the sample frame from college students to all the other types of community members.

\section{REFERENCES}

Aguinis, H. (2004). Regression analysis for categorical moderators. New York, NY: Guilford Press. 
Ajzen, I. (1985). Fromm intentions to actions: A theory of planned behavior. In J. Kuhl \& J. Beckmmann (Eds.), Action-control: From cognition to behavior (pp. 11-39). Heidelberg: Springer.

Ajzen, I. (1988). Attitudes, personality, and behavior. Chicago: Dorsey Press

Ajzen, I (1991). The theory of planned behavior. Organizational Behavior and Human Decision Processes, 50, 179-211.

Ajzen, I., \& Fishbein, M. (1980). Understanding attitudes and predicting social behavior. Englewood Cliffs, NJ: Prentice-Hall.

Albert, S., Ashforth, B. E., Barker, J. R., Dukerich, J. M., Elsbach, K. D., Glynn, M. A., Allen, L. R., Long, P. T., Perdue, R. R., \& Kieselbach, S. (1998). The impact of tourism development on residents' perceptions of community life. Journal of Travel Research 27(1): 1621.

Andereck, K. L., \& Vogt, C. A. (2000). “The relationship between residents' attitudes toward tourism and tourism development options." Journal of Travel Research 39 (1), 27-36.

Armitage, C. J., \& Conner, M. (2001). Efficacy of the theory of planned behavior: a metaanalytic review. British Journal of Social Psychology, 40, 471-499.

Baloglu, S., \& Mangaloglu, M. (2001). "Tourism Destination Images of Turkey, Egypt, Greece, and Italy as Perceived by U.S.-Based Tour Operators and Travel Agents." Tourism Management, 22: $1-9$.

Bauman, Z. (2001). Consuming Life, Journal of Consumer Culture, 1(1): 9-29. 
Becken, S. (2007). Tourists' perception of international air travel's impact on the global climate and potential climate change policies. Journal of Sustainable Tourism, 15(4), 351-368.

Bott, S., Cantrill, J. G., \& Myers, O. E. (2003). Place and promise of conservatory psychology. Human Ecology Review, 10(2): 100-112.

Charng, H-W., Piliavin, J. A., \& Callero, P. L. (1988). Role Identity and Reasoned Action in the Prediction of Repeated Behavior. Social Psychology Quarterly, 51(4): 303-17.

Collins, R. (2000). Situational Stratification: A Micro-Macro Theory of Inequality. Sociological Theory, 18(1): 14-43.

Desforges, L. (2000). Traveling the world: Identity and travel biography. Annals of Tourism Research, 27(4), 926-945.

Ellemers, N., Kortekaas, P., \& Ouwerkerk, J. W. (1999). Self-categorization, commitment to the group and group self-esteem as related but distinct aspects of social identity. European Journal of Social Psychology, 29, 371-389.

Fornell, C., \& Larcker, D. F. (1981). Evaluating structural equation models with unobservable variables and measurement error. Journal of Marketing Research, 18 (1), 39-50.

Gartner, W.C. (1996). Tourism Development. Principles, Process and Policies, John Wiley \& Sons Inc.

Gu, H., \& Ryan, C. (2008). Place attachment, identity and community impacts of tourism - the case of a Beijing hutong. Tourism Management, 29, 637-647. 
Gursoy, D., \& Rutherford, D. G. (2004), Host attitudes toward tourism: An improved structural model. Annals of Tourism Research, 31(3): 495-516.

Hagger, M. S., Anderson, M., Kyriakaki, M. K., \& Darkings, S. (2007). Aspects of identity and their influence on intentional behavior: comparing effects for three health behaviors. Personality and Individual Differences, 42: 355-367.

Hair, J. F. Jr., Anderson, R. E., Tatham, R. L., \& Black, W. C. (1998). Multivariate Data Analysis, (5th ed.), New Jersey, Prentice-Hall.

Kline, R. B. (2005). Principles and Practice of Structural Equation Modeling (2nd ed.). New York: Guilford.

MacCallum, R. C., Brown, M. W., \& Sugawara, H., M. (1996). Power Analysis and Determination of Sample Size for Covariance Structure Modeling. Psychological Methods, 1(2): 130-49.

McCool, S. F., \& Martin, S. R. (1994). Community attachment and attitudes toward tourism development. Journal of Travel Research, Winter, 29-34.

McCracken, G. (1986). "Clothing as Language: An Object Lesson in the Study of the Expressive Properties of Material Culture," in Material Anthropology: Contemporary Approaches to Material Culture, eds. Barrie Reynolds and Margarett Stott, New York: University Press of America, Inc.

Nauright, J. (1996). A Besieged tribe? Nostalgia, white cultural identity and the role of rugby in a changing South Africa. International Review for the Sociology of Sport, 31, 69-85.

Nunkoo, R., \& Gursoy, D. (2012). Residents' support for tourism: An identity perspective. Annals of Tourism Research 39(1): 243-268. 
Palme A., Koenig-Lewis N., \& Jones L. E. M. (2013). The effects of residents' social identity and involvement on their advocacy of incoming tourism, Tourism Management, 38, 142-151.

Pearce, P.L. (1998). The relationship between residents and tourists: The research literature and management directions. In W.F. Theobald (Ed.), Global tourism (2nd ed., pp. 129-149). Oxford, UK: Butterworth-Heinemann.

Sennett, R. (1999). Growth and Failure: The New Political Economy and its Culture. In:

Faetherstone \& Lash (ed): Spaces of Culture, City - Nation - World. SAGE Publications, London. p. 14-26.

Shamai, S. (1991). Sense of Place: an Empirical Measurement. Geoforum, 22 (3), 347-358.

Sirgy, M. J. (1986). Using self-congruity and ideal congruity to predict purchase motivation. Journal of Business Research, 13(1), 195-206.

Smith, J. M., \& Ingham, A. G. (2003). On the waterfront: Retrospectives on the relationship between sport and communities. Sociology of Sport Journal, 20, 252-274.

Song, H., Lee, C., Norman, W. C., \& Han, H. (2012). The Role of Responsible Gambling Strategy in Forming Behavioral Intention: An Application of a Model of Goal-Directed Behavior. Journal of Travel Research, 51(4) 512-523.

Sparks, P., \& Shepherd, R. (1992). Self-Identity and the Theory of Planned Behavior: Assessing the Role of Identification with "Green Consumerism". Social Psychology Quarterly, 55(4), 388399.

Stedman, R. (2002). Toward a Social Pyschology of Place: Predicting Behavior from Place Based Cognition, Attitude and Identity. Environment \& Behavior, 34, 561-581. 
Stets, J. E., \& Biga, C. F. (2003). Bringing identity theory into environmental sociology.

Sociological Theory, 21, 398-423.

Strack, F., \& Deutsch, R. (2004). Reflective and impulsive determinants of social behavior. Personality and Social Psychology Review, 8, 220-247.

Sukoco, B. M., \& Wu, W. Y. (2010). The personal and social motivation of customers' participation in brand community. African Journal of Business Management 4(5): 614 - 622.

Tajfel, H. (1972). Social categorization, "English manuscript of 'La categorization sociale," In Introduction a la Psychologie Sociale, ed. S. Moscovici, Paris: Larousse, 1: 272-302.

Tajfel, H. (1981). Social stereotypes and social groups. In J. C. Turner \& H. Giles (Eds.), Intergroup behavior (pp. 144-167). Oxford: Blackwell.

Tajfel, H. (1982). Social Identity and Intergroup Relations. Cambridge: Cambridge University Press.

Vernette E. (2003). Personnalité de la marque et image de soi, Les tendances du Marketing, ESCP-EAP, pp 1-21.

Visit Indy (2017). 500 Festival. Retrived on 11/10/2017, from:

https://www.visitindy.com/indianapolis-500-festival

Wang S. \& Chen, J. (2016). he influence of place identity on perceived tourism impacts. Annals of Tourism Research, 52: 16-28

Wang, S., \& Xu, H. (2015). Influence of Place-based Senses of Distinctiveness, Continuity, Selfesteem and Self-efficacy on Resident Attitudes toward Tourism. Tourism Management, pp.241250. 
Table 1. Measure Correlations, the Squared Correlations, and Measurement Properties $(\mathrm{N}=456)$

\begin{tabular}{|c|c|c|c|c|c|c|}
\hline \multicolumn{7}{|c|}{ Correlations between Latent Constructs (Squared) } \\
\hline Measures & CI & AI & ATT & SN & PBC & BI \\
\hline CI & 1 & $.51(.26)$ & $.36(.13)$ & $.39(.15)$ & $.45(.20)$ & $.43(.19)$ \\
\hline AI & $.51(.26)$ & 1 & $.60(.36)$ & $.72(.52)$ & $.51(.26)$ & $.75(.56)$ \\
\hline ATT & $.36(.13)$ & $.60(.36)$ & 1 & $.43(.19)$ & $.32(.10)$ & $.71(.50)$ \\
\hline SN & $.39(.15)$ & $.72(.52)$ & $.43(.19)$ & 1 & $.37(.14)$ & $.71(.50)$ \\
\hline PBC & $.45(.20)$ & $.51(.26)$ & $.32(.10)$ & $.37(.14)$ & 1 & $.47(.22)$ \\
\hline BI & $.43(.19)$ & $.75(.56)$ & $.71(.50)$ & $.71(.50)$ & $.47(.22)$ & 1 \\
\hline AVE & $57 \%$ & $79.6 \%$ & $59.7 \%$ & $55.5 \%$ & $69.2 \%$ & $79.3 \%$ \\
\hline mean & 5.41 & 4.57 & 5.29 & 5.21 & 4.52 & 4.79 \\
\hline $\begin{array}{c}\text { Cron- } \\
\text { bach's } \alpha\end{array}$ & .904 & .879 & .921 & .785 & .866 & .920 \\
\hline
\end{tabular}

Note: $\mathrm{CI}=$ personal identity, $\mathrm{AI}=$ social identity, $\mathrm{ATT}=$ attitude, $\mathrm{SN}=$ subjective norm, $\mathrm{PBC}=$ perceived behavioral control, $\mathrm{BI}=$ behavioral intentions, $\mathrm{AVE}=$ average variance extracted. $\mathrm{RMSEA}=$ root mean square error of approximation, $\mathrm{CFI}=$ comparative fit index, NFI $=$ normative fit index. Model measurement fit: $x^{2}=679.07(\mathrm{df}=$ $194, \mathrm{p}<.001)$, RMSEA $=0.072, \mathrm{CFI}=0.98, \mathrm{NFI}=0.97$.

Table 2. Standardized Maximum Likelihood Parameter Estimates $(\mathrm{N}=456)$

\begin{tabular}{|l|l|l|l|l|l|}
\hline \multicolumn{2}{|l}{ Paths } & $\begin{array}{l}\text { Standardized } \\
\text { Coefficients }\end{array}$ & T Value & $\begin{array}{l}\text { Results of hypothesis } \\
\text { testing }\end{array}$ \\
\hline CI & $\rightarrow$ & ATT & .06 & 1.30 & $\mathrm{H}_{1}:$ not supported \\
\hline AI & $\rightarrow$ & ATT & .57 & 10.90 & $\mathrm{H}_{2}:$ supported \\
\hline CI & $\rightarrow$ & SN & .26 & 4.31 & $\mathrm{H}_{3}:$ supported \\
\hline AI & $\rightarrow$ & SN & .28 & 6.41 & $\mathrm{H}_{4}:$ supported \\
\hline CI & $\rightarrow$ & PBC & .03 & .72 & $\mathrm{H}_{5}:$ not supported \\
\hline AI & $\rightarrow$ & PBC & .70 & 12.96 & $\mathrm{H}_{6}:$ supported \\
\hline CI & $\rightarrow$ & BI & -.01 & -.39 & $\mathrm{H}_{7}:$ not supported \\
\hline AI & $\rightarrow$ & BI & .22 & 3.78 & $\mathrm{H}_{8}:$ supported \\
\hline ATT & $\rightarrow$ & BI & .39 & 9.60 & $\mathrm{H}_{9}:$ supported \\
\hline SN & $\rightarrow$ & BI & .12 & 2.86 & $\mathrm{H}_{10}:$ supported \\
\hline PBC & $\rightarrow$ & BI & .34 & 6.87 & $\mathrm{H}_{11}:$ supported \\
\hline
\end{tabular}

Note: $\mathrm{CI}=$ Cognitive identity, $\mathrm{AI}=\mathrm{Affective}$ identity, $\mathrm{ATT}=$ attitude, $\mathrm{SN}=$ subjective norm, $\mathrm{PBC}=$ perceived behavioral control, $\mathrm{BI}=$ behavioral intentions, $\mathrm{AVE}=$ average variance extracted. $\mathrm{RMSEA}=$ root mean square error of approximation, $\mathrm{CFI}=$ comparative fit index, NFI = normative fit index. Goodness-of-fit statistics: $x^{2}=933.41(\mathrm{df}=$ 197, $\mathrm{p}<0.001$ ), RMSEA $=0.079, \mathrm{CFI}=0.97, \mathrm{NFI}=0.96$.

Table 3. Decomposition of Effects with Standardized Values

\begin{tabular}{l|llll|llll}
\hline \multicolumn{3}{c}{ Indirect Effect } & \multicolumn{5}{c}{ Total Effect } \\
\hline & ATT & SN & PBC & BI & ATT & SN & PBC & BI \\
CI & - & - & - & .07 & $.06^{*}$ & $.03^{*}$ & .26 & $.05^{*}$ \\
AI & - & - & - & .51 & .57 & .70 & .38 & .73
\end{tabular}




\begin{tabular}{|c|c|c|c|c|c|c|c|c|}
\hline ATT & - & - & - & - & - & & & .39 \\
\hline $\mathrm{SN}$ & - & - & - & - & - & - & - & .12 \\
\hline PBC & - & - & - & - & - & - & - & .34 \\
\hline
\end{tabular}

Table 4. Testing of the Moderating Effects of Past Behavior

\begin{tabular}{|c|c|c|c|c|c|c|c|c|c|}
\hline \multicolumn{4}{|c|}{ Step One - Interactive Effects Measurement } & \multicolumn{6}{|c|}{ Step Two - Simple Slope Analysis } \\
\hline $\begin{array}{l}\text { Regression } \\
\text { models }\end{array}$ & $\begin{array}{l}\text { Interaction- } \\
\text { term } \\
\text { Incremental } \\
\text { variance }\end{array}$ & $\begin{array}{l}\mathrm{F} \\
\text { change } \\
(\mathrm{df1}=1, \\
\mathrm{df} 2=439 \\
)\end{array}$ & p-value & $\begin{array}{l}\text { Regression } \\
\text { models }\end{array}$ & \begin{tabular}{|l} 
Past \\
Partici- \\
pation
\end{tabular} & Beta & $\mathrm{t}$ & P-value & $\begin{array}{l}\text { Adj. } \\
\text { R Sq. }\end{array}$ \\
\hline \multirow{2}{*}{$\begin{array}{l}\mathrm{PBC}=\mathrm{AI}+\mathrm{PP} \\
+\mathrm{AI} * \mathrm{PP}\end{array}$} & \multirow[t]{2}{*}{$6.2 \%$} & \multirow[t]{2}{*}{103.1} & \multirow[t]{2}{*}{.001} & \multirow[t]{2}{*}{$\mathrm{PBC}=\mathrm{AI}$} & low & .263 & 4.26 & .001 & .066 \\
\hline & & & & & high & .465 & 7.34 & .001 & .212 \\
\hline \multirow{2}{*}{$\begin{array}{l}\mathrm{SN}=\mathrm{CI}+\mathrm{PP}+ \\
\mathrm{CI} * \mathrm{PP}\end{array}$} & \multirow[t]{2}{*}{$14.8 \%$} & \multirow[t]{2}{*}{132.3} & \multirow[t]{2}{*}{.001} & \multirow[t]{2}{*}{$\mathrm{SN}=\mathrm{CI}$} & low & .256 & 4.11 & .001 & .062 \\
\hline & & & & & high & .381 & 5.79 & .001 & .141 \\
\hline \multirow{2}{*}{$\begin{array}{l}\mathrm{BI}=\mathrm{AI}+\mathrm{PP}+ \\
\mathrm{AI} * \mathrm{PP}\end{array}$} & \multirow[t]{2}{*}{$16.2 \%$} & \multirow[t]{2}{*}{95.7} & \multirow[t]{2}{*}{.001} & \multirow[t]{2}{*}{$\mathrm{BI}=\mathrm{AI}$} & low & .544 & 9.07 & .001 & .292 \\
\hline & & & & & high & .684 & 14.73 & .001 & .466 \\
\hline \multirow{2}{*}{$\begin{array}{l}\mathrm{BI}=\mathrm{ATT}+\mathrm{PP} \\
+\mathrm{ATT} * \mathrm{PP}\end{array}$} & \multirow[t]{2}{*}{$1.5 \%$} & \multirow[t]{2}{*}{13.7} & \multirow[t]{2}{*}{.001} & \multirow[t]{2}{*}{$\mathrm{BI}=\mathrm{ATT}$} & low & .652 & 13.36 & .001 & .422 \\
\hline & & & & & high & .658 & 11.92 & .001 & .430 \\
\hline \multirow{2}{*}{$\begin{array}{l}\mathrm{BI}=\mathrm{PBC}+\mathrm{PP} \\
+\mathrm{PBC} * \mathrm{PP}\end{array}$} & \multirow[t]{2}{*}{$6 \%$} & \multirow[t]{2}{*}{40.3} & \multirow[t]{2}{*}{.001} & \multirow[t]{2}{*}{$\mathrm{BI}=\mathrm{PBC}$} & low & .397 & 6.74 & .001 & .154 \\
\hline & & & & & high & .572 & 9.70 & .001 & .324 \\
\hline
\end{tabular}

Figure 1. The Conceptual Framework of Social Identity and Planned Behavior

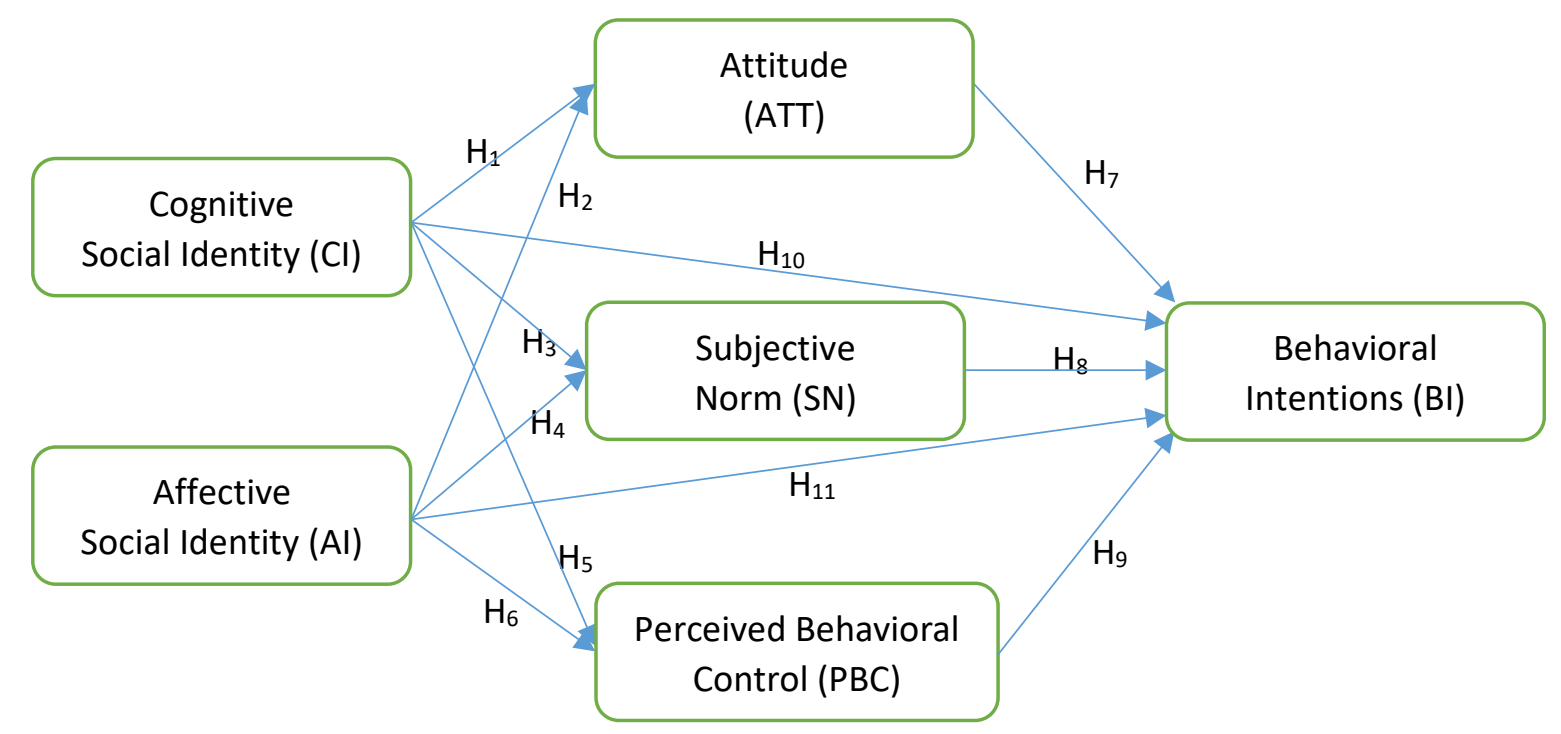


